\title{
Aspectos críticos para a compreensão da lógica estratégica no relacionamento entre organizações e comunidades
}

Critical aspects for understanding the strategic logic in the relationship between organizations and communities

Aspectos críticos para la comprensión de la lógica estratégica en el relacionamiento entre organizaciones y comunidades

\section{Márcio Simeone Henriques}

- Pós-doutor pela Universidade Nova de Lisboa, Portugal, com bolsa da Capes

- Doutor em Comunicação pela Universidade Federal de Minas Gerais (UFMG)

- Mestre em Educação pela Universidade Federal do Rio de Janeiro (UFRJ)

- Professor do Departamento de Comunicação Social da UFMG

- E-mail: simeone@ufmg.br 


\section{Resumo}

A visão das organizações sobre os públicos a que denominam "comunidades" tece uma lógica complexa onde entram em jogo alguns aspectos estratégicos que naturalizam a noção de comunidade, projetam e fazem emergir uma comunidade que se afirma no espaço público (de visibilidade), reduzem os múltiplos eixos de ação dos públicos locais e criam uma repartição dos interesses. Esses movimentos geram ambiguidades a partir das quais as tensões e os conflitos com este conjunto de públicos podem ser evidenciados e examinados.

\section{PALAVRAS-CHAVE: RELAÇÕES PÚBLICAS • COMUNIDADES • ORGANIZAÇÕES • ESTRATÉGIA.}

\section{Abstract}

The organizations' perception of the audiences they call "communities" weaves a complex logic which encompasses some strategic aspects that naturalize the notion of community, project and give rise to a community that affirms itself in the public space (of visibility), reduce the multiple axes of action of local audiences and create a sharing of the interests. These movements create ambiguities that allow the evidencing and examination of the tensions and conflicts with this set of audiences.

\section{KEYWORDS: PUBLIC RELATIONS • COMMUNITIES・ORGANIZATIONS • STRATEGY.}

\section{Resumen}

La visión de las organizaciones sobre los públicos a los que denominan "comunidades" teje una lógica compleja que involucra algunos aspectos estratégicos que naturalizan la noción de comunidad, proyectan y hacen emerger una comunidad que se afirma en el espacio público (de visibilidad), reducen los múltiples ejes de acción de los públicos locales y crean una repartición de intereses. Estos movimientos generan ambigüedades por las cuales las tensiones y los conflictos con este conjunto de públicos pueden ser resaltados y examinados. 


\section{ANO 14 • NÚMERO 26 • 10 SEM. 2017 • ORGANICOM ASPECTOS CRÍTICOS PARA A COMPREENSÃO DA LÓGICA ESTRATÉGICA NO RELACIONAMENTO ENTRE ORGANIZAÇÕES E COMUNIDADES}

U ma das atividades que têm desafiado as organizações na atualidade é a manutenção de relacionamentos com um conjunto de públicos que são agrupados sob a rubrica "comunidade" e que, em geral, se referem às populações que mantêm uma relação de proximidade e vizinhança com a organização e seus empreendimentos. A reflexão sobre esta questão, procurando entender melhor sua dinâmica, tão cheia de impasses e contradições, é algo emergente que se justifica principalmente por ser essa relação intrinsecamente conflituosa. Constitui uma atividade típica de relações públicas, no sentido em que se efetiva por atividades de mediação, onde se pode ver com clareza, em localidades circunscritas, a complexidade da formação e da movimentação de públicos em todas as suas nuances e também - por que não dizer? - a dimensão e 0 alcance das estratégias organizacionais.

Voltar esse olhar sobre as comunidades como público para as organizações, buscando desvelar a lógica sob a qual essas interações se estabelecem, pode ser um caminho propício para revelar aspectos que vão além dessas relações específicas, mas que dizem respeito também às próprias dinâmicas de relacionamento entre organizações e públicos, em outras dimensões. Trata-se não somente de produzir um conhecimento que melhor capacite as organizações para lidar com as controvérsias no âmbito local e extralocal, mas também de prover os próprios públicos desse saber sobre suas possibilidades e limites no contexto de conflitos de interesse e de grandes assimetrias de poder.

As perspectivas que apontam a erosão de um conceito convencional de comunidade (de cunho tradicional), fundada no compartilhamento de um território comum e baseada num sistema de fortes lealdades de vizinhança e parentesco (Tönnies, 2002; Schmitz, 1995), não são, contudo, suficientes para o enfrentamento das questões mais complexas que surgem. Isso pode ser percebido principalmente diante da persistência (mesmo que como práticas de resistência) de formas de lealdade e de sociabilidade comunais (como, por exemplo, em populações tradicionais, mas não somente nelas), como também de uma remissão constante a ideais normativos de comunidade como apelos sensíveis a modos de vida locais, mais enraizados, que povoam vocabulários políticos e sociais diferentes e até mesmo contraditórios.

A tradução desses ideais, no âmbito organizacional, leva a uma noção operacional de "comunidade de interesses", que evoca a ideia de alguma unidade conveniente, senão em termos de composição e comportamento desse conjunto populacional, pelo menos quanto a alguns aspectos problemáticos nas quais se implica e sobre os quais cabe uma posição em termos de suas vontades e interesses coletivos. Na prática organizacional coexistem as visões que exploram a comunidade como depositária dos valores e das solidariedades tradicionais e as que assumem uma noção baseada na partilha de interesses comuns que se agrupam numa localidade de formas diversas, multifacetadas e, no mais das vezes, imprevisíveis. Seja como for, sobressai sempre uma visão de unidade.

Entendemos que este paradoxo tem razão de ser, pois se insere numa tensão dinâmica entre geral e particular que é própria dos fenômenos de formação de públicos e de opinião pública e compõe, nas organizações, a constelação de discursos que as constituem e as justificam socialmente. Para alimentar essa reflexão, vamos explorar quatro aspectos estratégicos que desafiam a nossa compreensão sobre essas relações: (I) a naturalização da comunidade, (II) a emergência da comunidade visível, (III) as relações multiaxiais e (IV) a repartição dos interesses.

\section{A NATURALIZAÇÃO DA COMUNIDADE}

Sob o ângulo das organizações, a noção de uma comunidade do entorno conduz a uma ideia de naturalização de uma dada comunidade, que pode ser delimitada e, portanto, reconhecida por um aspecto objetivo. Assim, a referência aos públicos 
locais imediatamente se conecta a uma presumida unicidade, mesmo que ali se veja um conjunto muito heterogêneo de pessoas, grupos e instituições. Aí se encerra uma ambiguidade, já que, sob uma perspectiva operacional, as organizações admitem a composição diversificada dessa população e suas múltiplas articulações, mas, ao mesmo tempo, voltam-se, por meio do discurso, a uma "comunidade de interesses", ou seja, a um conjunto de interesses presumidos que nela preexistem e são tomados, de algum modo, como consensuais.

Na prática, as organizações buscam aferir esse interesse comum a partir dos vários pontos verificáveis em cada segmento que conseguem definir. Ora, essa composição de interesses não poderia ser, de modo algum, naturalizada, já que é fruto da ação e da movimentação desses públicos locais, com seus inerentes conflitos. Entretanto, a remissão que a organização faz a qualquer presumido interesse comum é fruto de sua própria visão sobre os públicos locais, onde ela mesma contabiliza, arredonda e totaliza, segundo seus próprios critérios, uma comunidade que habita sua vizinhança. 0 problema é se aquilo que se chama de comunidade pode ser algo definido por alguma natureza intrínseca, objetivável.

Com isso não se evidencia apenas que esse olhar é arbitrário e redutor, mas também que se almeja um conjunto de relações mais naturalizadas e estáveis que, em geral, tem a organização como centro (Henriques, 2014). 0 que nos chama a atenção são as razões pelas quais a comunidade naturalizada se torna uma figura de certo modo atraente. Por certo não há uma só razão, mas podemos lançar algumas hipóteses, dentre elas:

(a) A persistência da ideia tradicional de comunidade-como destaca Bauman (2003), existe uma nostalgia das comunidades tradicionais, baseada nas velhas lealdades (de vizinhança e parentesco), tida como um local de aconchego e segurança, em contraste com os imperativos da modernidade, que desafiam fortemente essa noção, especialmente pela crescente urbanização. Em certa medida, essa aposta comunitária, mesmo que carregada dos estereótipos aplicados ao termo "comunidade", busca mesmo evocar um tipo ideal que, sem dúvida, soa como algo bom e desejável.

(b) A comunidade como mera figura de generalização de interesses - Neste sentido, funciona analogamente à utilização da ideia geral de opinião pública. 0 movimento generalizador é fundamental para a formulação de um interesse coletivo e, mais além, de um interesse público (Henriques, 2010). Assim, a remissão totalizante à comunidade como operador de um interesse público é um fator importante para dar volume a um conjunto de interesses e justificá-los publicamente.

Em ambos os casos, essa operação é essencialmente retórica. Mas o que, de fato, materializa uma "comunidade" para a organização é uma oscilação paradoxal entre a comunidade como lugar de dissenso e de consenso, entre uma visão de conflitos particulares (e particularizados) e uma visão geral idealizada, entre as visões estáticas e dinâmicas desse agrupamento a que se dá o nome de comunidade. Essas indagações nos levam a um segundo aspecto: a comunidade que emerge dessa relação e se torna visível (publicizada) a partir do movimento estratégico das organizações, onde ela é, de algum modo, projetada.

\section{A EMERGÊNCIA DA COMUNIDADE VISÍVEL}

Não há que negar a tensão intrínseca entre consenso e dissenso, entre conflito e cooperação, que vale para qualquer ente coletivo. Porém, quando falamos de públicos, falamos desses agrupamentos em condição pública, ou seja, que não apenas deve considerar as relações que se dão entre os indivíduos e entre esses agrupamentos (menos ou mais estáveis), em seu caráter privado (suas disputas, negociações, barganhas), mas sob um regime de publicidade, portanto, de visibilidade, ou 
seja, relações que ocorrem sob certas condições específicas e numa lógica que transcenda (ou pretenda transcender) os particularismos. É exatamente este o ponto que nos remete à questão da afirmação e reconhecimento de uma comunidade, já que estamos lidando com o conjunto de interações que carecem todo o tempo de buscar aceitação mutuamente controlada por todos os que nela se envolvem (numa situação ideal de publicidade, onde todos exercem uma vigilância sobre todos e agem uns de acordo com as ações dos outros).

Sob esta perspectiva, a estratégia organizacional opera no contexto de um jogo complexo de influências - não limitadas ao âmbito organização-comunidades. Uma das principais formas de articulação dessa influência reside na própria capacidade de a organização ser captadora e editora de discursos sobre os públicos (os que ela considera relevantes), de construir coerências e, de certo modo, consensos, que são propostos publicamente com grande potência. Com isso ressalta um ponto fundamental: as organizações não produzem e difundem apenas discursos sobre si mesmas, mas também sobre os seus públicos, em sua generalidade (explícita ou tacitamente), incluindo aí o que chama de "comunidade". Sendo assim, em certo sentido, as organizações "criam" públicos. No caso, projetam e fazem nascer discursivamente uma "comunidade".

Pelo lado dessas comunidades, a interinfluência dos públicos numa localidade busca aumentar a sua potência - em termos da capacidade de influir no desenrolar de uma situação concreta que se estabeleça frente tanto às organizações quanto ao poder público. Cada público, tomado isoladamente em sua especificidade, possui interesses particulares, mas precisa se esforçar para persuadir os outros de que suas causas, razões e propósitos possuem algum interesse geral, ou seja, concorrem para a formação de um interesse público no âmbito daquele local, executando, mesmo que de modo difuso, o mesmo movimento de generalização.

Assim, esse conjunto também se empenha em construir e editar algo comum que se torne visível, gerando um sentido de público. Com isso se pode dizer que também os públicos locais constroem alguma imagem totalizante de si mesmos que expõem com o intuito de buscar apoio e aceitação no âmbito extralocal (da sociedade), também constroem uma "comunidade" publicamente afirmada. Assim, a comunidade que se dá a ver pela projeção da organização não corresponde, necessariamente, às situações particulares vivenciadas numa localidade ou mesmo às generalizações feitas e apresentadas pelos próprios públicos locais que emergem na relação como sendo a sua própria "comunidade" de interesses, o que equivale a dizer que as imagens feitas pela organização e pelos públicos de comunidade (tomados "como uma unidade") tendem a competir, inclusive, sobre sua identidade. Assim, tanto a organização quanto os públicos locais tendem a definir a "sua" comunidade, que pode ter pontos em comum, mas de todo modo se afirma publicamente de maneira distinta. Conforme evoluem as tensões e os conflitos nessa relação tendem a se evidenciar as distinções entre uma comunidade naturalizada que a organização projeta e a comunidade emergente, que se assume como tal exatamente em função dessa relação problemática.

\section{AS RELAÇÕES MULTIAXIAIS}

Como terceiro ponto a refletir, seria importante nos referirmos à teia complexa de relações composta por interinfluências dinâmicas entre os diversos públicos numa localidade. Não devemos observar somente a composição diversificada dos públicos, à qual já nos referimos, mas também importa o tipo de interações que mantêm entre si. Estas não podem ser figuradas apenas como relações um-outro. Por um lado, as influências de um para outro segmento podem ocorrer privadamente, numa esfera que diz respeito somente a uma negociação (ou composição) entre as próprias partes e a ninguém mais. Neste caso, importa dar contas aos públicos das consequências disso, caso essa ação venha à luz (e afete a outras partes). Por outro, 
a busca de influência de um para muitos (ou virtualmente sobre todos) depende inexoravelmente de alcançar os meios de visibilidade e de ter maior habilidade e capacidade de lidar com os recursos de publicidade naquele local.

Tanto as possibilidades de justificar publicamente as ações quanto as de totalizar e generalizar opiniões e interesses são sempre realizadas com base nas capacidades e habilidades de oferecer algo à esfera do visível. Isso configura uma potência de ação, motivo pelo qual os públicos buscam mobilizar outros públicos e compor alianças, ou seja, sua ação sempre é referente a outros públicos (Babo, 2013). Esse conjunto de interações em vários eixos, tanto convergentes como divergentes, impõe uma dificuldade de visualização e compreensão quando não é tomado a partir de alguns aspectos singulares sobre os quais possa incidir um foco. Também neste caso, a visão da organização sobre os públicos locais tende a ser simplificadora. A habilidade estratégica da organização está em tentar identificar, dentre estes eixos, aqueles que possuam maior potencial de interinfluências, o que exige certa acurácia. Dificilmente poderia ser diferente, já que isso implica uma relação objetiva de eficácia desejada na ação. Também aqui, uma simplificação generalizante na forma como as organizações projetam a comunidade como um público é bastante conveniente e estratégica, já que com isso podem reconhecer menos ou mais essas interinfluências, reforçando aquelas que lhes são mais favoráveis e minimizando os possíveis impactos desfavoráveis de outras.

Uma questão a anotar é referente à mídia e ao poder público local, que cumprem um papel dúbio nesse processo. Tanto imprensa quanto governo são considerados primariamente em relação ao interesse público (como depositários, defensores, árbitros), mas também em relação aos seus interesses particulares. É fato que são agentes fundamentais que interferem nessa teia relacional complexa no ambiente (especialmente se levamos em conta a distribuição do poder e da visibilidade no âmbito local). Para a organização não é questão simples equacionar o esquema relacional com esses atores de modo coerente. Tanto a mídia quanto o poder público sempre aparecerão de modo ambíguo, por mais que as suas atitudes possam ser vistas como favoráveis ou que haja algum tipo de negociação privada com esses agentes. Quando se fala da rubrica "comunidade", é isso que justifica que o mapeamento feito pela organização inclua esses dois segmentos, mas sempre destacando suas singularidades. Também essa ambiguidade se apresenta do ponto de vista dos próprios públicos, que igualmente oscilam entre a confiança e a desconfiança, ou seja, nem a imprensa nem o poder público são plenamente confiáveis para nenhuma das partes e ambas têm que se esforçar para obter essa confiança.

Tudo isso que observamos se refere unicamente ao nível da localidade, como se essa teia pudesse se encerrar sobre si mesma. Entretanto, cabe considerar que todas essas relações transbordam das fronteiras da localidade, o que não é nosso objetivo tratar aqui, mas que, evidentemente, complica ainda mais a compreensão do processo.

\section{A REPARTIÇÃO DOS INTERESSES}

Um quarto aspecto relevante é relativo à forma como as organizações lidam estrategicamente com os interesses, já que isso configura um ponto nevrálgico acerca da relação que estabelecem ou desejam estabelecer com os públicos. Em favor dessa centralidade lembremos que a questão do interesse está plenamente consolidada na prática e no ethos das relações públicas ("harmonizar interesses", "equilibrar interesses privados e públicos", "favorecer o interesse público"), mas também em outras proposições, tais como a de "defender publicamente interesses privados" ou de "gerir relacionamentos com as partes interessadas". Diante do que a organização classifica como "comunidade", tida operacionalmente como uma "comunidade de interesses", é imperativo que ela rastreie os diversos interesses que podem estar em jogo numa localidade, para poder traduzi-los em expectativas e em demandas concretas, ou seja, o mero interesse deve ser objetivado em algo que deve aparecer como ação efetiva de relacionamento. 
As organizações podem proceder a esse rastreamento com menor ou maior escuta e participação da comunidade. Seja como for, essa leitura não é feita simplesmente por um voo panorâmico sobre esse conjunto de públicos. Ao contrário, informam as boas práticas que a organização deva recorrer a esse procedimento em dois movimentos complementares: um classificatório (relativoà segmentação eà rotulação que se dá num mapeamento) e outro putativo(relativo ao julgamento-figurado, presumível - que faz da legitimidade dos públicos e de seus respectivos interesses). Como já afirmamos, a leitura desses públicos pelas organizações é feita fundamentalmente pelos interesses (numa ideia de comunidade de interesses), sendo, assim, passível de uma avaliação e hierarquização própria, que permita compreender o que está em jogo. Os processos de segmentação envolvem inevitavelmente uma análise de riscos e uma definição de prioridades segundo esse critério - podemos lembrar aqui que a teoria dos stakeholders vincula estritamente o grau de influência dos públicos aos riscos na tomada de decisão (Freeman, 2010).

Um dos fatores que fundamentam essa lógica de segmentação é justamente o fato de que a nomeação de um segmento já implica uma expectativa de ação, ou seja, uma atitude reconhecível desses públicos. Assim, no mapeamento dos públicos, quando se identifica um agrupamento e se lhe aplica um rótulo (moradores, líderes comunitários, ativistas, torcedores, fiéis etc.), evidenciam-se prontamente atitudes que são mais ou menos esperadas, segundo repertórios de ação codificados. Outro fator tem a ver com as formas de lidar, como tática, com os interesses específicos, buscando atender de forma particularizada às expectativas e demandas de pelo menos uma parte desses grupos. A lógica aqui evidenciada baseia-se no axioma de que a satisfação individual de alguns segmentos pode arrefecer os questionamentos mais gerais e granjear apoio, ao menos momentâneo, em termos de imagem. Mas possui também outro lado, ao desmontar algumas solidariedades e alianças que possam existir entre alguns desses segmentos. Para além da facilidade de lidar com os interesses mais específicos, divididos, classificados e separados - porque assim podem ser mais bem interpretados e traduzidos em demandas bem concretas -, busca-se com isso interferir diretamente no mapa dos possíveis conflitos. Em alguns casos, essas atenções dirigidas infundem nos públicos sentimentos no mínimo ambíguos. Este é um princípio pouco declarado, porém fundamental, da chamada "comunicação dirigida". Porém, atender às demandas particulares não é garantia de atendimento às demandas mais gerais e mais difusas - mas a tática aqui é de que, ao fazer isso, as partes possam ser tomadas pelo todo.

Há também um problema de fundo com a questão dos interesses, mais especificamente com a sua identificação e análise: sua leitura nunca é segura e completa. Uma vez manifestos, os interesses precisam traduzir-se em posições e demandas menos ou mais definidas (onde a pergunta fundamental é: "o que eles querem?"). Sempre há um déficit de compreensão, correspondente a parte dos interesses que não são explicitados, uma vez que a expressão de uma demanda não pode ser tomada como correspondente a todos os interesses envolvidos na questão. Sempre haverá algo de presumido no interesse do(s) outro(s) - e uma desconfiança em relação ao que não se explicita. A repartição dos interesses, portanto, não garante sequer que se compreendam plenamente as atitudes e ações de cada segmento particular.

Além disso, a exposição pública de cada interesse particular está sempre sujeita a um escrutínio que se baseia tanto na reputação quanto na legitimidade. A reputação, neste caso, é efeito do movimento que aqui denominamos de putativo, atribuindo valores presumíveis a quem manifesta esses interesses, de tal modo que possamos acreditar e confiar. A legitimidade de quem manifesta o interesse está em linha direta com essa reputação, mas não se confunde com ela (um agente pode ser considerado legítimo, mas sem reputação suficiente, motivo pelo qual terá menor credibilidade). E não só isso: a legitimidade também depende de uma consideração moral acerca do interesse em si - razoabilidade e justiça da demanda manifesta e do que ela provavelmente representa dos interesses dos quais essa demanda é expressão. Isso define, pelo lado da organização, uma seleção e um enquadramento dos interesses, o que, ao fim, é também onde reside boa parte da sua estratégia em relação às comunidades e de sua intervenção política. 


\section{CONSIDERAÇÕES FINAIS}

A exploração desses aspectos críticos nos conduz, portanto, a uma breve síntese que evidencia o caráter estratégico e algumas alternativas de ação que estão presentes nessas relações entre as organizações e as comunidades:

- A visão naturalizada da comunidade é importante para possibilitar a totalização e a generalização dos públicos locais, fornecendo, inclusive, uma base estética para esse processo. A comunidade e as relações comunitárias se tornam idealizações convenientes e sedutoras. Além disso, este movimento tende a superestimar a homogeneidade em detrimento da diversidade e os consensos em detrimento dos dissensos num dado âmbito localizado.

- A comunidade que emerge no espaço de visibilidade sugere que não é possível uma imagem unívoca, mas aparece como uma categoria de referência para a delimitação do alcance das ações - tanto da organização quanto dos públicos em relação a ela -, sendo uma construção arbitrária a partir da centralidade organizacional. 0 que entra em jogo é uma tensão na produção de sentidos sobre a comunidade e o comunitário, nas formas pelas quais organização e comunidade se reconhecem (ou não) mutuamente.

- As relações multiaxiais abrem mais claramente a questão das estratégias de mobilização por parte dos públicos e da tática simplificadora adotada pelas organizações. Isso acarreta a necessidade de ver esse processo numa teia complexa de relações de interinfluência e que produzem ao mesmo tempo eixos de convergência e de divergência.

- A repartição dos interesses envolve um raciocínio no qual somos levados a desconfiar fortemente da noção de "comunidade de interesse" (ou mesmo das tão faladas "partes interessadas"), tal como é apropriada pelas organizações para definir esse conjunto de públicos locais.

À ideia de uma comunidade que não preexiste objetivamente, mas que é construída na relação pública que se estabelece, juntam-se, portanto, as evidências do poder organizacional de afirmar e justificar discursivamente uma unidade comum e (re)interpretar seus interesses, classificando-os e traduzindo-os em demandas. Este processo, a nosso ver, se encontra na base da estratégia de uma organização de construir o seu potencial de influência. De outro lado está um conjunto de públicos, que vivem numa área de vizinhança sob o impacto imediato das operações organizacionais. Eles estão imersos numa complexa teia de interinfluências nos âmbitos locais e extralocais, cujo potencial depende de sua capacidade de articulação e mobilização em torno de questões públicas; isso se dá no embate com as organizações, pela disputa em torno de sua própria afirmação pública "como uma unidade" e pela oscilação ambígua entre a resistência e a cooperação. Estas são algumas pistas importantes para a compreensão e avaliação crítica das práticas estratégicas de relacionamento com os públicos locais e daquilo que se possa chamar de comunidade como forma política e de sociabilidade nos dias atuais.

\section{REFERÊNCIAS}

BABO, Isabel. 0 acontecimento e os seus públicos. Comunicação e sociedade, v. 23, p. 218-234, 2013.

BAUMAN, Zygmunt. Comunidade: a busca por segurança no mundo atual. Rio de Janeiro: Jorge Zahar, 2003. 
HENRIQUES, Márcio S. Comunicação e mobilização social na prática de policia comunitária. Belo Horizonte: Autêntica, 2010.

A cultura e o poder na relação entre organizações e comunidades: aspectos reveladores In: Sociedade, comunidade e redes. São Caetano do Sul, SP: Difusão, 2014. p. 49-62.

SCHMITZ, Kenneth. Comunidade: a unidade ilusória. In: MIRANDA, Orlando de (Org.). Para ler Ferdinand Tönnies. São Paulo: Edusp, 1995. p. 177-193.

TÖNNIES, Ferdinand. Community and society. New York (USA): Dover Publications, 2002.

Texto recebido em 21.04.2017 e aprovado em 10.05.2017. 